\title{
Daniel Ménager, Érasme
}

\section{Filippo Fonio}

\section{(2) OpenEdition}

\section{Journals}

\section{Edizione digitale}

URL: http://journals.openedition.org/studifrancesi/34452

DOI: 10.4000/studifrancesi.34452

ISSN: 2421-5856

\section{Editore}

Rosenberg \& Sellier

\section{Edizione cartacea}

Data di pubblicazione: 1 novembre 2005

Paginazione: 396

ISSN: 0039-2944

\section{Notizia bibliografica digitale}

Filippo Fonio, «Daniel Ménager, Érasme», Studi Francesi [Online], 146 (XLIX | II) | 2005, online dal 30

novembre 2015, consultato il 20 avril 2021. URL: http://journals.openedition.org/studifrancesi/34452 ; DOI: https://doi.org/10.4000/studifrancesi.34452

\section{Questo documento è stato generato automaticamente il 20 avril 2021.}

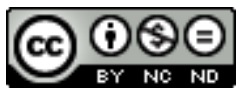

Studi Francesi è distribuita con Licenza Creative Commons Attribuzione - Non commerciale - Non opere derivate 4.0 Internazionale. 


\title{
Daniel Ménager, Érasme
}

\author{
Filippo Fonio
}

\section{NOTIZIA}

DANIEL MÉNAGER, Érasme, Paris, Desclée de Brouwer («Biographies»), 2003, pp. 181.

1 Questa biografia dell'umanista di Rotterdam (ca. 1469-1536) ha il pregio di costituire un agile strumento per chi desideri avere una visione d'insieme della figura, del pensiero e degli scritti di Erasmo. In questo caso ciò non prescinde da un taglio scientifico di tutto rispetto, come è da aspettarsi da uno specialista quale Daniel Ménager. Interessante è la bipartizione del volume. A una sezione Approches, introduzione a questioni di più ampio respiro per meglio comprendere la figura di Erasmo attivo partecipante alle vicende della sua epoca, fa seguito una sezione biografica, Étapes, che presenta appunto le tappe della vita dell'umanista, sempre con attenzione anche alla situazione culturale dell'Europa fra Quattro e Cinquecento. Da Approches è possibile desumere alcune fra le tematiche principali dell'opera di Erasmo, in particolare l'importanza della dissimulazione e dei 'discorsi secondi', della brevitas da un lato e della copia dall'altro, il logocentrismo che nella sua riflessione tocca anche la sfera religiosa, l'ironia socratica. Il volume concede molto spazio al dibattito critico, e Ménager tiene a suggerire caute interpretazioni su aspetti del pensiero erasmiano dei quali tuttora si discute. Lo studioso fra l'altro fa il punto della situazione in merito all'atteggiamento tenuto da Erasmo nelle querelles che lo hanno visto impegnato per gran parte della vita, in particolare a seguito della traduzione del Nuovo Testamento e, più tardi, con Lutero. Una certa attenzione è dedicata alla riflessione di Erasmo circa il contemptus mundi, il primato dell'esegesi nei confronti della teologia, la sua diffidenza nei confronti della Scolastica, o la questione dell'antisemitismo erasmiano. Ménager si sofferma sugli scritti dotati di una certa verve (la festivitas umanistica), la Laus stultitiae e i Colloquia, ma anche su alcune opere caratterizzate da una particolare fortuna, come l'Enchiridion militis christiani, oppure interessanti per ciò che concerne i generi e le forme (gli Adagia ad esempio, risposta di Erasmo ai repertori di loci communes diffusi all'epoca). Mediante la rievocazione di una figura immersa in rivalità, amicizie e una costante ricerca di 
protettori potenti - senza ciononostante abdicare a una certa libertà intellettuale, lo studio di Ménager non trascura le dinamiche sociali dell'epoca di Erasmo, occupandosi anche del mercato editoriale e delle sue leggi, o dei fitti scambi fra gli intellettuali europei. Non ultimo pregio del volume è quello di aggiornare celebri profili dell'umanista olandese, fra cui lo studio di Johann Huizinga, alla luce di metodologie più attente allo specifico letterario oltre che allo storico-sociale. 